\title{
KINERJA PANTI SOSIAL BINA WANITA "MELATI" PROVINSI KALIMANTAN SELATAN
}

\author{
Ade Hermawan ${ }^{1}$ \\ Widarto $^{2}$ \\ Email : stiabb08@gmail.com \\ STIA Bina Banua Banjarmasin
}

\begin{abstract}
The "Melati" Women's Social Institution of South Kalimantan Province carries out social rehabilitation in the form of social guidance activities and skills guidance for socio-economic vulnerable women. The "Melati" Women's Social Institution of South Kalimantan Province has a fairly good performance in providing social guidance and skills guidance to women who are socio-economically vulnerable. All indicators used to measure the performance of social guidance and skills guidance carried out by the "Melati" Women's Social Institution of South Kalimantan Province, namely productivity, service quality and accountability, showed good performance results.
\end{abstract}

Keywords: Social Institution, service quality

\section{PENDAHULUAN}

Masalah wanita rawan sosial ekonomi perlu ditangani dengan serius agar tidak semakin banyak jumlahnya, sehingga perlu diberi pelatihan keterampilan yang berupaya merehabilitasi wanita rawan sosial ekonomi sehingga dapat diterima kembali dimasyarakat dan bisa menyiapkan masa depan yang lebih baik dengan keterampilan yang sudah diperoleh.

Keterampilan yang dimiliki diharapkan membawa perubahan bagi wanita rawan sosial ekonomi. Kecakapan merupakan keterampilan yang harus dimiliki oleh seseorang untuk menghadapi permasalahan atau problem hidup sehingga dapat hidup secara wajar dalam kehidupanya.

Program keterampilan dimaksudkan untuk memberikan bekal pada wanita rawan sosial ekonomi yang terkait dengan kebutuhan pasar kerja, peluang usaha, potensi ekonomi atau industri yang ada di masyarakat. Keterampilan diberikan untuk meningkatkan pengetahuan dan sikap warga belajar dibidang yang sesuai dengan kebutuhan, bakat dan 
minatnya sehingga memiliki bekal untuk bekerja secara mandiri untuk dapat meningkatkan kualitas hidupnya.

Salah satu tempat rehabilitasi sosial dikota Banjarbaru yang menerima wanita rawan sosial ekonomi adalah Panti Sosial Bina Wanita "Melati” Provinsi Kalimantan Selatan yang wilayah kerjanya di provinsi Kalimantan Selatan.

Di tempat ini wanita rawan sosial ekonomi mendapatkan pembinaan dengan berbagai program kegiatan, program pelatihan keterampilan kerja dan pembinaan mental ini diharapkan memberi manfaat yang besar bagi para wanita rawan social ekonomi. Proses rehabilitasi wanita rawan sosial ekonomi ini tentunya butuh waktu, sarana dan tangan-tangan ahli untuk memberikan pendampingan dan pengabdian. Sehingga diharapkan mereka bisa menjadi manusia lebih baik yang tidak kembali kepada dunia wanita rawan sosial ekonomi. Program ini bisa disebut prospektif karena menuntut adanya keberlanjutan. Program ini selain focus untuk para wanita rawan sosial ekonomi juga menyentuh kepada Dinas Sosial Provinsi Kalimantan Selatan khususnya Panti Sosial Bina Wanita "Melati" Provinsi Kalimantan Selatan, yang sifatnya berperan untuk meningkatkan kemampuan mereka agar lebih mumpuni dalam memberikan pelayanan kepada wanita rawan sosial ekonomi agar mampu terjun di masyarakat dan memiliki bekal keahlian keterampilan kerja dan juga mental yang baik agar tidak terjerumus ke masa lalu mereka sebagai wanita rawan sosial ekonomi.

Berdasarkan uraian masalah yang dikemukakan di atas, maka penelitian ini bertujuan untuk mengetahui kinerjaPanti Sosial Bina Wanita "Melati” Provinsi Kalimantan Selatan dalam melaksanakan rehabilitasi sosial pada wanita rawan sosial ekonomi.

\section{TINJAUAN TEORITIS}

Pedoman Penyusunan laporan Akuntabilitas Kinerja Instansi Pemerintah yang dikeluarkan oleh LAN Nomor 589/IX/6/Y/1999 (1999:3) menyebutkan pengertian kinerja sebagai gambaran mengenai tingkat pencapaian pelaksanaan suatu kegiatan atau program kebijaksanaan dalam mewujudkan sasaran, tujuan, misi dan visi organisasi. Penilaian terhadap kinerja merupakan hal yang sangat penting karena dapat dijadikan ukuran keberhasilan suatu organisasi dalam kurun waktu tertentu.

Kinerja dapat diartikan sebagai gambaran yang mengenai tingkat pencapaian pelaksanaan suatu kegiatan atau program atau kebijakan dalam mewujudkan sasaran,tujuan,misi, dan visi organisasi yang tertuang dalam rencana strategi suatu 
organisasi. Pernyataan tentang visi dan misi yang jelas harus sesuai dengan budaya dan kebutuhan perusahaan dan kebutuhan pasar, sehingga dapat menumbuhkan komitmen karyawan terhadap perkerjaan dan memupuk semangat kerja karyawan, menumbuhkan rasa keharmonisan di dalam kerja karyawan dan menumbuhkan standar kerja yang prima.

Menurut Keban (2003:25) mengatakan bahwa konsep kinerja organisasi (Performance) dapat didefinisikan sebagai sebuah pencapaian hasil atau degree of accomplishtment. Hal ini berarti bahwa, kinerja suatu organisasi itu dapat dilihat dari tingkatan sejauh mana organisasi dapat mencapai tujuan yang di dasarkan pada tujuan yang sudah ditetapkan sebelumnya.

Menurut Dwiyanto (2003:32) mengatakan bahwa, "kesulitan dalam pengukuran kinerja organisasi pelayanan publik sebagian muncul karena tujuan dan misi organisasi publik seringkali bukan hanya kabur akan tetapi juga bersifat multidimensional.

Namun ada beberapa indikator yang biasanya digunakan untuk mengukur kinerja birokrasi publik Dwiyanto (2003:35) yaitu sebagai berikut:

1. Produktifitas, Konsep produktivitas tidak hanya mengukur tingkat efisiensi, tetapi juga efektivitas pelayanan. Produktivitas pada umumnya dipahami sebagai rasio antara input dengan output.

2. Kualitas Pelayanan, Kepuasan masyarakat bisa menjadi parameter untuk menilai kinerja organisasi publik.

3. Responsivitas, adalah kemampuan organisasi untuk mengenali kebutuhan masyarakat menyusun agenda dan prioritas pelayanan dan mengembangkan program-program pelayanan publik sesuai dengan kebutuhan dan aspirasi masyarakat.

4. Responsibilitas menjelaskan apakah pelaksanaan kegiatan organisasi publik itu dilakukan sesuai dengan prinsip-prinsip administrasi yang benar atau sesuai dengan kebijakan organisasi, baik yang eksplisit maupun implicit.

5. Akuntabilitas publik menunjukan pada seberapa besar kebijakan dan kegiatan organisasi publik tunduk pada para pejabat politik yang dipilih oleh rakyat, asumsinya adalah bahwa para pejabat politik tersebut karena dipilih oleh rakyat, dengan sendirinya akan selalu merepresentasikan kepentingan rakyat.

Rehabilitasi dilihat dari makna kata berasal dari bahasa inggris yaitu rehabilitation, artinya mengembalikan seperti semula. Rehabilitasi adalah pemulihan kepada kedudukan 
(keadaan, nama baik) yang dahulu (semula), perbaikan anggota tubuh yang cacat dsb atas individu (misal pasien rumah sakit,korban bencana) supaya menjadi manusia yang berguna dan memiliki tempat di masyarakat (Kamus Besar Bahasa Indonesia, 2002:940).

Soekanto (1985:423), rehabilitasi sebagai suatu proses atau teknik mendidik kembali serta mengarahkan kembali dan motivasi pelanggar atau penjahat, sehingga perilakunya sesuai dengan aturan-aturankemasyarakatan.

Rehabilitasi yang dimaksud dalam penelitian ini adalah proses perbaikan atau membangun dalam menanggulangi pekerja seks komersial agar dapat berkarya sesuai dengan harkat dan martabat dan menjadi anggota masyarakat.

Pengertian rehabilitasi dimaksud adalah mengembalikan kemampuan yang pernah dimilikinya, karena suatu hal musibah ia harus kehilangan kemampuannya, kemampuan yang hilang inilah yang dikembalikan seperti semula yaitu seperti kondisi sebelum terjadi musibah yang dialami. Sosial berarti segala sesuatu mengenai masyarakat, yang perduli terhadap lingkungan umum.

Jadi pengertian rehabilitasi sosial secara umum adalah proses yang dilakukan secara terus-menerus dalam rangka pemulihan kembali manusia agar bisa teratasi masalahnya yang meliputi; pemulihan kembali kepercayaan diri, mandiri serta tanggung jawab pada diri, keluarga, masyarakat ataupun lingkungan sosialnya.

Sesuai dengan sifatnya yang rehabilitatif, maka bentuk penanganan masalahsosialinimerupakanusahakelompoksasarantertentu,dalam halini adalah bagian dari kehidupan masyarakat yang menjadi penyandang masalah (Soetomo, 2008:53)

Menurut Soetomo langkah pelaksanaan rehabilitasi sebagai berikut:

1.Tahap I dentifikasi, Masalah sosial merupakan fenomena yang selalu munculdalam kehidupan masyarakat, perwujudannya dapat merupakan masalah lama yang mengalamiperkembangan, akan tetapi dapat pula merupakan masalah baru yang muncul karena perkembangan dan perubahan kehidupan sosial, ekonomi dan kultural, masalah sosial dianggap sebagai kondisi yang tidak diinginkan oleh karena dapat membawa kerugian baik secara fisik maupun nonfisik pada individu, kelompok maupun masyarakat. Secara keseluruhan, atau dapat juga merupakan kondisi yang dianggap bertentangan dengan nilai, norma atau standar sosial. 
2. Tahap Diagnosis, Setelah masalah sosial teridentifikasi, maka akan mendorong munculnya respon dari masyarakat, berupa tindakan bersama untuk memecahkan masalah, berupa tindakan bersama untuk memecahkan masalah. Tahap diagnosis dilakukan untuk upaya mencari dan mempelajari latar belakang masalah, faktor yang terkait dan terutama faktor yang menjadi penyebab atau sumber masalah. Hal ini sangat membantu untuk menentukan tindakan sebagai upaya pemecahan masalah.

Dengan menggunakan cara berpikir yang sederhana, banyak orang beranggapan bahwa masalah sosial terjadi oleh karena ada hal yang salah atau kurang benar dalam kehidupan masyarakat. Dengan demikian mendiagnosis masalah sosial pada dasarnya adalah mencari sumber kesalahan. Berkaitan dengan hal ini, Eitzen (1987:12) membedakan adanya dua pendekatan yaitu 1) person blame approach dengan melakukan diagnosis lebih menempatkan individu sebagai unit analisisnya. Maka dalam pemecahan masalah akan menawarkan tindakan penanganan penyandang masalah berupa berbagai bentuk rehabilitasi dan resosialisasi perilaku; 2) system blame approach yang lebih memfokuskan pada sistem sebagai unit analisis untuk mencari dan menjelaskan sumber masalahnya. Sistem ini melakukan pendekatan untuk memberikan rekomendasi pemecahan masalah berupa perubahan dan perbaikan kinerja sistemnya.

3.Tahap Treatment atau upaya pemecahan masalah adalah apabila dapat menghapus atau menghilangkan masalahnya dari realitas kehidupan sosial. Namun treatment tidak harus diartikan sebagai upaya untuk menghilangkan masalah sosial, akan tetapi dapat mengurangi atau membatasi perkembangan masalah.

Treatment atau penanganan masalah sosial mempunyai cakupan yang luas, tidak terbatas pada tindakan rehabilitative berupa upaya untuk melakukan perubahan atau perbaikan terhadap kondisi yang dianggap bermasalah. Usaha untuk melakukan pencegahan agar masalahsosialtidakterjadiatau paling tidak mengantisipasi dan meminimalisasi kemungkinan munculnya kondisi yang tidak diharapkan juga menjadi bagian dari penanganan masalah sosial. Di samping itu, menciptakan dan mengembangkan iklim yang kondusif dalam kehidupan baik individu maupun masyarakat juga merupakan faktor yangmemberikan daya dukung bagi penanganan masalah sosial. 


\section{METODE PENELITIAN}

Lokasi penelitian ini bertempat di Panti Sosial Bina Wanita "Melati" Provinsi Kalimantan Selatan yang beralamat diJalan Jenderal Ahmad Yani km. 30 RT 03 No. 09 Kelurahan Guntung Payung kecamatan Landasan Ulin Kota Banjarbaru. Penelitian ini dilaksanakan selama \pm 4 bulan yaitu bulan Oktober 2020 sampai Januari 2021.

Metoda yang dipergunakan dalam penelitian ini adalah metoda Deskriptif, yaitu suatu metoda penelitian yang bertujuan guna memberikan gambaran terhadap pelaksanaan suatu program/ kegiatan. Artinya penelitian ini bertujuan memberikan gambaran secara faktualkinerja Panti Sosial Bina Wanita "Melati" Provinsi Kalimantan Selatan dalam melaksanakan rehabilitasi sosial pada wanita rawan sosial ekonomi.

Data yang diperoleh dalam penelitian ini adalah data primer dan data sekunder. Data primer dalam penelitian ini adalah data hasil pendapat dari informan (staff Panti Sosial Bina Wanita "Melati" Provinsi Kalimantan Selatan) dan key informan (Kepala Panti Sosial Bina Wanita "Melati" Provinsi Kalimantan Selatan) mengenai kinerja Panti Sosial Bina Wanita "Melati" Provinsi Kalimantan Selatanyang diperoleh melalui wawancara dan observasi. Dan data dari hasil kuisoner dari wanita rawan sosial ekonomi mengenai kinerja Panti Sosial Bina Wanita "Melati" Provinsi Kalimantan Selatan.

Data sekunder ialah data pendukung yang diperlukan dalam pembuatan laporan hasil penelitian yang terdiri dari :

1. Profil Panti Sosial Bina Wanita "Melati” Provinsi Kalimantan Selatan.

2. Peraturan perundang-undangan yang mengatur mengenai Panti Sosial Bina Wanita.

Teknik pengumpulan data yang dipergunakan dalam penelitian ini adalah sebagai berikut :

1. Kuisioner

Yaitu data dikumpulkan dengan cara menyampaikan daftar pertanyaan mengenai masalah penelitian untuk dijawab oleh responden .

2. Dokumentasi

Yaitu data dikumpulkan dari dokumen-dokumen yang berkaitan dengan masalah penelitian. 
Data yang berhasil dikumpulkan diolah kemudian hasilnya dimasukan ke dalam tabel distribusi frekuensi untuk kemudian diberikan penjelasan serta dinterpretasikan. Teknik analisa data dilakukan secara kualitatif.

Definisi Operasional Kinerja adalah produktivitas, kualitas pelayanan, dan akuntabilitas rehabilitasi sosial yang dilakukan oleh Panti Sosial Bina Wanita "Melati" Provinsi Kalimantan Selatan kepada wanita rawan sosial ekonomi.

Rehabilitasi sosial adalah pemberian bimbingan latihan dan keterampilan yang diberikan oleh Panti Sosial Bina Wanita "Melati" Provinsi Kalimantan Selatan kepada wanaita rawan sosial ekonomi.

\section{HASIL DAN PEMBAHASAN}

Panti Sosial Bina Wanita Melati merupakan salah satu Unit Pelaksana Teknis dari Departemen sosial RI mulai beroperasi sejak tanggal 1 April 1982 berdasarkan Surat Keputusan Menteri Sosial Republik Indonesia Nomor 5/HUK/1982 dan diresmikan tanggal 20 November 1982. Dan sekarang ini statusnya adalah sebagai Unit Pelaksana Teknis Dinas Sosial Provinsi Kalimantan Selatan.

Tugas pokok Panti Sosial Bina Wanita Melati Provinsi Kalimantan Selatan adalah melaksanakan pelayanan dan rehabilitasi sosial bagi wanita rawan sosial ekonomi meliputi pembinaan fisik, mental, sosial dan keterampilan dalam rangka terwujudnya keselarasan dan kemandirin wanita rawan sosial ekonomi agar dapat berperan aktif dalam kehidupan bearmasayarakat.

Visi Panti Sosial Bina Wanita Melati Provinsi Kalimantan Selatan adalah : "Terwujudnya Kesejahteraan dan Kemandirian Wanita Rawan Sosial Ekonomi"

Misi Panti Sosial Bina Wanita Melati Provinsi Kalimantan Selatan adalah :

1. Meningkatkan rasa harga diri, percaya diri dan kesadaran dan tanggung jawab terhadap diri sendiri keluarga dan masyarakat dan lingkungan sosialnya.

2. Meningkatkan kreatifitas berkarya dan pengembangan potensi diri wanita rawan sosial ekonomi.

3. Meningkatkan profesionalisme profesi pekerjaan sosial dalam pelayanan rehabilitasi sosial di dalam maupun diluar panti.

4. Menumbuhkan dan meningkatkan kesadaran dan tanggung jawab bagi panati. 
5. Menjalin kerja sama yang baik dengan sumber-sumber yang tersedia untuk pemberdayaan peningkatan kemandirin wanita awan sosial ekonomi.

6. Menjalin kerja sama dengan organisasi masyarakat dan instansi terkait dalam rangka meningkatkan pelayanan kesejahteraan bagi wanita rawan sosial ekonomi.

Fungsi Panti Sosial Bina Wanita Melati Provinsi Kalimantan Selatan adalah :

1. Menyusun rumausan kebijakan teknis pelaksanaan pelayanan kesejahteraan sosial wanita rawan sosial ekonomi yang mencakup program pelayanan, pemmbinaan dan rehabilitasi sosial.

2. Mengindentifikasi kebutuhan pelayanan,pembinaan dan pelatihan keterampilan.

3. Melaksanakan kegiatan pelayanan dan rehabiitasi sosial bagi wanita rawan sosial ekonomi yang mencakup kegiatan pendekatan awal, penerimaan, rehabilitasi sosial, bimbingan keterampilan, resosialisasi, pembinaan lanjut dan terinasi bagi wanita rawan sosial ekonomi.

4. Melaksanakan motivasi sosial bersama masyarakat, pihak swasta dan instansi terkait untuk menanggulangi masalah sosial dan peningkatan ketahanan sosial keluarga dan masyarakat.

5. Pengelolaan urusan ketatausahaan.

Proses penanganan di Panti Sosial Bina Wanita Melati Provinsi Kalimantan Selatan adalah :

1. Tahap pendekatan awal

Tahap pendekatan awal terdiri dari kegiatan sosialisasi, orientasi dan konsultasi, identifikasi, motivasi, dan seleksi.

2. Tahap penerimaan

Tahap penerimaan terdiri dari kegiatan registrasi dan pengungkapan masalah (assesment).

3. Tahap bimbingan sosial dan keterampilan

Tahap bimbingan sosial dan keterampilan terdiri dari kegiatan bimbingan fisik, bimbingan mental, bimbingan sosial, bimbingan keterampilan usaha/ kerja.

4. Tahap resosialisasi

Tahap resosialisasi terdiri dari kegiatan bimbingan kesiapan dan peran serta masyarakat, bimbingan sosial hidup bermasyarakat, bimbingan pembinaan bantuan 
stimulan usaha produktif, bimbingan pengembangan usaha/ kerja produktif, bimbingan kewirausahaan, penempatan dan penyaluran.

5. Tahap pembinaan lanjut

Tahap pembinaan lanjut terdiri dari kegiatan bimbingan peningkatan kehidupan bermasyarakat, bantuan pengembangan usaha/ peningkatan keterampilan, bimbingan peningkatan usaha.

6. Tahap terminasi

Yaitu pemutusan hubungan dan kerja sama pembinaan dengan eks klien Panti Sosial Bina Wanita Melati Provinsi Kalimantan Selatan.

Kegiatan rehabilitasi pada Panti Sosial Bina Wanita Melati Provinsi Kalimantan Selatan meliputi kegiatan penerimaan dan kegiatan bimbingan latihan dan keterampilan.

Prosedur kegiatan rehabilitasi pada Panti Sosial Bina Wanita Melati Provinsi Kalimantan Selatan meliputi :

1. Pendaftaran seleksi dan motivasi awal yang dilaksanakan oleh Panti Sosial Bina Wanita Melati Provinsi Kalimantan Selatan bekerja sama dengan Dinas Sosial pemeringah kabupaten/ kota.

Sasaran rehabilitasi adalah wanita rawan sosial ekonomi, yaitu perempuan dewasa menikah/ belum menikah, janda dan tidak mempunyai penghasilan cukup untuk dapat memenuhi kebutuhan sendiri dan keluarganya dan juga bermasalah secara sosial. Peryaratan agar dapat mengikuti rehabilitasi di Panti Sosial Bina Wanita Melati Provinsi Kalimantan Selatan adalah : usia antara 20-50 tahun, belum menikah, janda (boleh nikah tapi dengan persetujuan suami, sehat jasmani dan rohani, tidak dalam keadaan hamil, bisa baca tulis, putus sekolah, bersedia tinggal di asrama dan memenuhi aturan yang berlaku keterangan tidak mampu dari desa/ kelurahan setempat, surat rekomendasi dari dinas sosial kabupaten/ kota.

2. Kegiatan rehabilitasi di Panti Sosial Bina Wanita Melati Provinsi Kalimantan Selatan terdiri dari kegiatan :

a. Orientasi

Kegiatan orientasi pada Panti Sosial Bina Wanita Melati Provinsi Kalimantan Selatan meliputi kegiatan pengenalan lingkungan, pengenalan program, peraturan baris berbaris, pengenalan staf Panti Sosial Bina Wanita Melati Provinsi Kalimantan Selatan, instruktur dan materi bimbingan 
b. Bimbingan sosial

Bimbingan sosial pada Panti Sosial Bina Wanita Melati Provinsi Kalimantan Selatan meliputi kegiatan bimbingan mental, psikologis, dan keagamaan, bimbingan budi pekerti, bimbingan kedisiplinan, dan bimbingan olah raga.

c. Bimbingan keterampilan

Bimbingan keterampilan pada Panti Sosial Bina Wanita Melati Provinsi Kalimantan Selatan meliputi bimbingan keterampilan pilihan dan keterampilan yang diikuti seluruh klien. Keterampilan pilihan terdiri dari tata busana, tata rias/ salon dan tata boga. Sedangkan keterampilan yang diiukuti seluruh klien meliputi keagamaan, pelatihan komputer dasar, pembuatan kain sasirangan, pembuatan kain perca dan keterampilan home industri.

Dalam penelitian ini kinerja Panti Sosial Bina Wanita "Melati” Provinsi Kalimantan Selatan, diukur dengan menggunakan tiga indikator, yaitu produktivitas, kualitas pelayanan, dan akuntabilitas yang dihubungkan dengan Tujuan Panti Sosial Bina Wanita "Melati" Provinsi Kalimantan Selatan. Artinya kinerja Panti Sosial Bina Wanita "Melati" Provinsi Kalimantan Selatan dapat diketahui dari Produktivitas, kualitas pelayanan dan akuntabilitas Panti Sosial Bina Wanita "Melati" Provinsi Kalimantan Selatan dalam menjalankan bimbingan sosial dan bimbingan keterampilan kepada wanita rawan sosial ekonomi.

1. Produktifitas

Produktivitas Panti Sosial Bina Wanita "Melati" Provinsi Kalimantan Selatan diukur dengan indikator kemampuan organisasi dalam menjalankan bimbingan sosial dan bimbingan keterampilan.

Tabel 2 Produktivitas Bimbingan Sosial

\begin{tabular}{|l|l|c|c|}
\hline No. & \multicolumn{1}{|c|}{ Produktivitas } & Frekuensi & Persentase \\
\hline 1. & Produktif & 10 & 25 \\
2. & Cukup produktif & 29 & 72,5 \\
3. & Tidak produktif & 1 & 2,5 \\
\hline \multicolumn{2}{|c|}{ Jumlah } & 40 & 100 \\
\hline
\end{tabular}

Tabel 2 menunjukkan produktivitas bimbingan sosial Panti Sosial Bina Wanita "Melati" Provinsi Kalimantan Selatan. Dari 40 orang responden 10 orang menyatakan produktif, 29 orang menyatakan cukup produktif, dan 1 orang menyatakan tidak produktif. Artinya terdapat kecenderungan bahwa produktivitas 
Panti Sosial Bina Wanita "Melati" Provinsi Kalimantan Selatan dalam melaksanakan pembinaan kepribadian adalah cukup produktif.

Tabel 3 Produktivitas Bimbingan keterampilan

\begin{tabular}{|l|l|c|c|}
\hline No. & \multicolumn{1}{|c|}{ Produktivitas } & Frekuensi & Persentase \\
\hline 1. & Produktif & 12 & 30 \\
2. & Cukup produktif & 27 & 67,5 \\
3. & Tidak produktif & 1 & 2,5 \\
\hline \multicolumn{2}{|c|}{ Jumlah } & 40 & 100 \\
\hline
\end{tabular}

Tabel 3 menunjukkan produktivitas bimbingan keterampilan Panti Sosial Bina Wanita "Melati" Provinsi Kalimantan Selatan. Dari 40 orang responden 12 orang menyatakan produktif, 27 orang menyatakan cukup produktif, dan 1 orang menyatakan tidak produktif. Artinya terdapat kecenderungan bahwa produktivitas Panti Sosial Bina Wanita "Melati" Provinsi Kalimantan Selatan dalam Pembinaan Kemandirian adalah cukup produktif.

2. Kualitas Pelayanan

Kualitas Pelayanan Panti Sosial Bina Wanita “Melati” Provinsi Kalimantan Selatan diukur dengan indikator kemampuan organisasi dalam menjalankan bimbingan sosial dan bimbingan keterampilan kepada warga binaan.

Tabel 4 Kualitas Bimbingan Sosial

\begin{tabular}{|l|l|c|c|}
\hline No. & \multicolumn{1}{|c|}{ Kualitas Pelayanan } & Frekuensi & Persentase \\
\hline 1. & Berkualitas & 10 & 25 \\
2. & Cukup berkualitas & 29 & 72,5 \\
3. & Tidak berkualitas & 1 & 2,5 \\
\hline \multicolumn{2}{|c|}{ Jumlah } & 40 & 100 \\
\hline
\end{tabular}

Tabel 4 menunjukkan kualitas bimbingan sosial Panti Sosial Bina Wanita "Melati" Provinsi Kalimantan Selatan. Dari 40 orang responden 10 orang menyatakan berkualitas, 29 orang menyatakan cukup berkualitas, dan 1 orang menyatakan tidak berkualitas. Artinya terdapat kecenderungan bahwa kualitas bimbingan sosial Panti Sosial Bina Wanita “Melati” Provinsi Kalimantan Selatan adalah cukup berkualitas.

Tabel 5 Kualitas Bimbingan Keterampilan

\begin{tabular}{|l|l|c|c|}
\hline No. & \multicolumn{1}{|c|}{ Kualitas Pelayanan } & Frekuensi & Persentase \\
\hline 1. & Berkualitas & 12 & 30 \\
\hline
\end{tabular}




\begin{tabular}{|l|l|c|c|}
\hline 2. & Cukup berkualitas & 27 & 67,5 \\
3. & Tidak berkualitas & 1 & 2,5 \\
\hline \multicolumn{2}{|r|}{ Jumlah } & 40 & 100 \\
\hline
\end{tabular}

Tabel 5 menunjukkan kualitas Bimbingan keterampilan Panti Sosial Bina Wanita "Melati" Provinsi Kalimantan Selatan. Dari 40 orang responden 12 orang menyatakan berkualitas, 27 orang menyatakan cukup berkualitas, dan 1 orang menyatakan tidak berkualitas. Artinya terdapat kecenderungan bahwa bimbingan keterampilanyang dilaksanakan Panti Sosial Bina Wanita "Melati" Provinsi Kalimantan Selatan adalah cukup berkualitas.

3. Akuntabilitas

Akuntabilitas Panti Sosial Bina Wanita "Melati" Provinsi Kalimantan Selatan diukur dengan indikator kemampuan organisasi dalam menjalankan bimbingan sosial dan bimbingan keterampilan kepada warga binaan.

Tabel 6 Akuntabilitas Bimbingan Sosial

\begin{tabular}{|l|l|c|c|}
\hline No. & \multicolumn{1}{|c|}{ Akuntabilitas } & Frekuensi & Persentase \\
\hline 1. & Akuntabel & 10 & 25 \\
2. & Cukup Akuntabel & 29 & 72,5 \\
3. & Tidak akuntabel & 1 & 2,5 \\
\hline \multicolumn{2}{|c|}{ Jumlah } & 40 & 100 \\
\hline
\end{tabular}

Tabel 6 menunjukkan Akuntabilitas bi bingan sosialPanti Sosial Bina Wanita "Melati" Provinsi Kalimantan Selatan. Dari 40 orang responden 10 orang menyatakan akuntabel, 29 orang menyatakan cukup akuntabel, dan 1 orang menyatakan tidak akuntabel. Artinya terdapat kecenderungan bahwa Pembinaan Kepribadian Panti Sosial Bina Wanita "Melati” Provinsi Kalimantan Selatan adalah cukup akuntabel.

Tabel 7 Akuntabilitas Bimbingan Keterampilan

\begin{tabular}{|l|l|c|c|}
\hline No. & \multicolumn{1}{|c|}{ Akuntabilitas } & Frekuensi & Persentase \\
\hline 1. & Akuntabel & 12 & 30 \\
2. & Cukup Akuntabel & 27 & 67,5 \\
3. & Tidak akuntabel & 1 & 2,5 \\
\hline \multicolumn{2}{|c|}{ Jumlah } & 40 & 100 \\
\hline
\end{tabular}


Tabel 7 menunjukkan Akuntabilitas bimbingan sosialPanti Sosial Bina Wanita "Melati" Provinsi Kalimantan Selatan. Dari 40 orang responden 12 orang menyatakan akuntabel, 27 orang menyatakan cukup akuntabel, dan 1 orang menyatakan tidak akuntabel. Artinya terdapat kecenderungan bahwa Bimbingan sosial Panti Sosial Bina Wanita “Melati” Provinsi Kalimantan Selatan adalah cukup akuntabel.

Berdasarkan hasil dan analisa yang telah peneliti uraikan tersebut dapat disimpulkan bahwa Semua indikator yang digunakan untuk mengukur kinerja bimbingan sosial dan bimbingan keterampilan yang dilakukan oleh Panti Sosial Bina Wanita "Melati" Provinsi Kalimantan Selatanyaitu produktifitas, kualitas pelayanan dan akuntablitas menunjukan hasil kinerja yang cukup baik.

\section{KESIMPULAN}

Dengan mengacu pada tujuan penelitian dan berdasarkan hasil temuan serta pembahasan yang telah dilakukan pada bab sebelumnya maka dapat ditarik kesimpulan bahwa :

1. Rehabilitasi sosial yang dilakukan oleh Panti Sosial Bina Wanita "Melati" Provinsi Kalimantan Selatan adalah berupa kegiatan bimbingan sosial dan bimbingan keterampilan kepada wanita rawan sosial ekonomi.

2. Panti Sosial Bina Wanita "Melati" Provinsi Kalimantan Selatanmemiliki kinerja yang cukup baik dalam melakukan bimbingan sosial dan bimbingan keterampilan kepada wanita rawan sosial ekonomi. Semua indikator yang digunakan untuk mengukur kinerja bimbingan sosial dan bimbingan keterampilan yang dilakukan oleh Panti Sosial Bina Wanita "Melati" Provinsi Kalimantan Selatan yaitu produktifitas, kualitas pelayanan dan akuntablitas menunjukan hasil kinerja yang cukup baik.

\section{DAFTAR PUSTAKA}

Ahmad Batinggi, 1999, Manajerial Pelayanan Umum, Universitas Terbuka Jakarta Arikunto, Suharsimi, 2002. Prosedur Penelitian. PT. Rineka Cipta. Jakarta.

Basuki, 2021, Pengantar Metode Penelitian Kuantitatif, Media Sains Indonesia. Bandung

Daha, Khairid, 2002. Kinerja Organisasi PelayananPublik. Hand out perkuliahan Matrikulasi,MAP UGM. Yogyakarta

Dwiyanto,Agus,dkk.2003. Reformasi Birokrasi Publik di Indonesia.PSKK UGM. Yogyakarta

Handayaningrat, 1996 Pengantar Administrasi Negara, Ghalia Indonesia, Jakarta 
Harsono Hs,C.I.1995. Sistem Baru Pembinaan Narapidana.Jakarta:Djambatan

Mangunhardjana, AM. 1991. Pembinaan Arti dan Metodenya. Yogyakarta: Kanisius

Munir, 2000, Manajemen Pelayanan Publik, Bina Aksara, Jakarta

Miles, Mattew B dan Huberman, Michael A. 1992. Analisa Data Kualitatif. Jakarta: University Indonesia-PRESS

Moleong, LexyJ., 2005. Metodologi Penelitian Kualitatif. Bandung: PT Remaja Rosda karya Offset

Sugiyono, 2006. Metode Penelitian Administrasi. AlfaBeta. Bandung

Sugiyono.2007. Metode Penelitian Kualitatif dan R\&D. Alfabeta. Bandung

Peraturan Gubernur Provinsi Kalimantan Selatan No. 76 tahun 2011 tentang SOP peserta Pendidikan Wanita Rawan Sosial Ekonomi Panti Sosial Bina Wanita "Melati" Provinsi Kalimantan Selatan. 